\title{
CLINICAL MANAGEMENT OF FAMILIES WITH HEREDITARY COLORECTAL CANCER SYNDROMES
}

\author{
Monica Dandapani, MS, CGC ${ }^{1}$ and Elena M. Stoffel, MD, MPH \\ Cancer Risk and Prevention Clinic, Dana-Farber Cancer Institute, Boston, MA
}

\begin{abstract}
Hereditary colorectal cancer syndromes can be associated with a lifetime risk of CRC of $>70 \%$ in the absence of specialized surveillance. Diagnosing a genetic predisposition to cancer allows clinicians to tailor cancer prevention strategies for patients and families at highest risk. Once a genetic syndrome has been identified in a family, communication with family members, timely implementation of screening tests and/or surgeries, and psychosocial support are all instrumental for effective cancer prevention.

Molecular screening of tumors, computerized risk assessment models, and genetic testing can help clinicians identify individuals at risk for hereditary cancer syndromes. This review discusses some of the complexities involved in the diagnosis and management of families with hereditary CRC syndromes and provides strategies for coordinating clinical care.
\end{abstract}

\section{Keywords}

Hereditary colorectal cancer; FAP; HNPCC; genetic counseling and testing; family members

\section{Introduction}

Cancer affects families. Because colorectal cancer (CRC) is the third most common cancer in the United States, many people have had a close relative diagnosed with CRC. However, for the 5-6\% of CRC cases associated with hereditary colorectal cancer syndromes, this diagnosis has profound implications for the family and will affect the management of relatives for generations to come. Fortunately, CRC is preventable, and there is good evidence that colonoscopic surveillance reduces morbidity and mortality from CRC not only in sporadic tumors, but also in inherited CRC syndromes.(1) However, individuals with a hereditary predisposition to cancer require more intensive screening than what is routinely recommended for close relatives of a patient with sporadic CRC.(2-4) In cases of familial adenomatous polyposis (FAP), the risk of CRC approaches 100\% in the absence of endoscopic and/or surgical intervention and children in families affected with FAP should begin endoscopic screening by age 10 or 11 . Lynch syndrome (also known as Hereditary

(C) 2011 Elsevier Inc. All rights reserved.

Mailing Address: Elena M. Stoffel, MD, MPH, Smith Building Room 234, Dana-Farber Cancer Institute, 44 Binney St, Boston, MA 02115, Office: 617-632-5022, Fax: 617-632-4088, estoffel@partners.org.

${ }^{1}$ Certified Genetic Counselor

Publisher's Disclaimer: This is a PDF file of an unedited manuscript that has been accepted for publication. As a service to our customers we are providing this early version of the manuscript. The manuscript will undergo copyediting, typesetting, and review of the resulting proof before it is published in its final citable form. Please note that during the production process errors may be discovered which could affect the content, and all legal disclaimers that apply to the journal pertain.

No disclosures/conflicts of interest 
Non-Polyposis Colorectal Cancer or HNPCC), is the most common hereditary CRC syndrome and is associated with a lifetime risk of CRC and endometrial cancer of approximately $70 \%$ and $40 \%$, respectively.(5) Lynch-associated neoplasms often develop at young ages and demonstrate an accelerated progression, $(6,7)$ justifying annual endoscopic surveillance beginning as early as age $20,(2-4)$ as well as screening for endometrial cancer for women.(8)

However, the process by which a family is identified as being at high risk can be complex. It requires that a clinician can elicit an accurate family history, recognize the features of the different hereditary cancer syndromes, and recommend the required colorectal and extracolonic surveillance. In order for the full benefit of genetic testing to be realized, the patient must then effectively communicate this information to members of the extended family. This review will outline the complexities involved in caring for families with hereditary CRC syndromes and provide some strategies for facilitating their clinical management.

\section{Challenge \#1: Making the diagnosis of a hereditary CRC syndrome}

Patients with hereditary CRC rarely present with this label. If a 30 year old presents with rectal bleeding and has the classic phenotype of 100s-1000s of colorectal adenomas, the diagnosis of familial adenomatous polyposis syndrome (FAP) may seem obvious. However, if prior to the diagnosis this patient's only complaint was that his father had CRC at age 42, some clinicians may not have recommended a colonoscopy. Furthermore, if this same 30 year old was diagnosed with CRC in the absence of other adenomas, some may not suspect a hereditary cancer syndrome at all.

Under ideal circumstances, a patient with a personal or family cancer history suspicious for a hereditary CRC syndrome would be referred for genetic evaluation, undergo genetic testing which revealed a pathogenic gene mutation, and would then communicate this information to all at-risk family members so they could also be tested to determine whether they inherited the genetic predisposition to cancer. However, for many individuals at-risk for hereditary CRC syndromes genetic evaluation is never initiated because clinicians lack information regarding other cancer diagnoses in the family and/or do not recognize the potential for genetic predisposition.(9)

Lynch Syndrome is estimated to account for approximately 3-5\% of all CRC; yet because this syndrome lacks a distinctive phenotype, many of these patients may not be recognized as having hereditary colorectal cancer. Studies have demonstrated that fewer than half of individuals with Lynch Syndrome have family histories which meet the classic Amsterdam Criteria (initially used to define the syndrome).(10-12) Furthermore, the revised Bethesda Guidelines may still miss as many as $28 \%$ of MMR gene mutation carriers.(13-15) Because Lynch Syndrome can be difficult to identify and has important implications for the surgical management and surveillance of CRC patients and their families, experts have proposed implementing universal pathology screening of CRC tumors, testing for tumor microsatellite instability (MSI) and immunohistochemical (IHC) expression of MMR proteins.(15-19) This approach to identifying families with Lynch Syndrome has its limitations, as it depends upon (A) having a proband diagnosed with a CRC tumor demonstrating the phenotype of defective mismatch repair, and (B) referring the family for further genetic evaluation.(20)

Yet often the first individual who seeks genetic evaluation is not a CRC patient, but rather an unaffected member of a family in which a number of people have died of CRC. In situations in which this "unaffected" individual undergoes genetic testing and a pathogenic gene mutation is found, this confirms the diagnosis in the family. However, a majority of these genetic tests yield results which are either clinically indeterminate/uninformative or 
variants of uncertain clinical significance (VUCS). Having access to detailed information about ages of diagnosis and types of cancer in the family can confirm suspicion (or provide reassurance) that a hereditary cancer syndrome is more (or less) likely.

In order to collect additional data which might confirm or exclude the possibility of a hereditary cancer syndrome, it may be necessary to involve other family members in the genetic evaluation process.

Consider the following case: A 36y female presented for genetic evaluation because of her family history of colon cancer. Her father died of CRC at age 60. With the permission of the deceased individual's wife, the genetic counselor requested the father's medical records to rule out polyposis and review details of his cancer diagnosis. Pathology records indicated that the tumor had been tested with IHC for MMR proteins and demonstrated absence of expression of the MLH1 protein. A doctor's note documented a discussion encouraging his CRC patient to undergo a genetic evaluation, but this was never completed. In light of this information, the unaffected young woman opted to undergo genetic testing for Lynch Syndrome, which did not reveal any mutations in MLH1, MSH2, or MSH6 genes and was clinically indeterminate. The genetics team encouraged the patient to contact her father's sister. This individual had recently been diagnosed with endometrial cancer and the genetics team coordinated her genetic testing which revealed a pathogenic mutation in MLH1, confirming the family's diagnosis of Lynch Syndrome and changing the unaffected young woman's genetic test result from "indeterminate" to "true negative."

Knowledge of a true positive genetic test result in a surviving cancer-affected relative can help clinicians re-interpret the meaning of a test result which might otherwise be clinically uninformative. Furthermore, confirming the presumed diagnosis of a hereditary cancer syndrome gives other family members the opportunity to undergo informative genetic testing to stratify their cancer risk. In cases in which testing yields a genetic variant of uncertain clinical significance (VUCS), reaching out to family members is essential. Does the variant track with cancer in the family? Is there another pathogenic mutation known in the family? Eventually, information may emerge to re-classify the variant as either pathogenic or benign (polymorphism) through molecular assays; $(21,22)$ however this may take years, during which time clinicians will have to make decisions regarding how best to manage individuals at-risk.

In classic familial adenomatous polyposis (FAP), genetic testing reveals a pathogenic mutation in the APC gene in $90 \%$ of cases. Biallelic mutations in MYH can produce a similar polyposis phenotype (albeit with an autosomal recessive pattern of inheritance); however there remain some families who have clinical FAP without an identified genetic mutation. For other syndromes such as attenuated polyposis, juvenile polyposis, and PeutzJeghers syndrome, genetic testing may be informative in only $50 \%$ of cases. In these cases it is important to understand that a negative genetic test does not exclude the diagnosis of a hereditary cancer syndrome; it merely means that the option of predictive genetic testing will not be available to other at-risk individuals, who will need to be managed as if they are potentially affected.

\section{Challenge \#2: Family communication about inherited cancer syndromes}

Even under the best of circumstances, communication among family members can be complicated. When the subject matter is cancer, conversations can become emotionally charged, and some family members may refuse to even talk about cancer.(23)

Consider the following case: A 50yo man presented to a colorectal surgeon with his second diagnosis of CRC, after having been diagnosed with his first CRC 20 years prior. 
The patient had been undergoing colonoscopies every 5 years. The surgeon recognized the patient's last name and realized he had previously operated on this patient's cousin who had also been diagnosed with CRC at a young age. Although the patient knew that his cousin had been diagnosed with CRC, he was not aware that his cousin had undergone genetic testing which revealed that he carried a pathogenic MMR mutation associated with Lynch Syndrome. Because of privacy laws, the surgeon could not disclose the information about the cousin's genetic diagnosis to his patient, but he did refer him for genetic evaluation.

Unfortunately, information about genetics and hereditary cancer syndromes can be difficult for patients to understand, and even more challenging to explain to their family members. Privacy rules prevent clinicians from contacting a patient's relatives to disclose genetic test results.(24) Professional societies (including the American Society for Human Genetics (ASHG), American College of Medical Genetics (ACMG) and the American Society for Clinical Oncology (ASCO)) have concluded that the ethical duty to warn is satisfied if the clinician informs the patient that the genetic condition has implications for the health of other family members and encourages the patient to tell relatives of these risks. As a result, patients are often left to communicate this complicated information to family members themselves. Our survey of individuals undergoing genetic testing for Lynch syndrome demonstrated that 1 in 4 mutation carriers did not share information about their test result with relatives beyond their immediate family.(25) In most cases individuals reported that they did not deliberately decide to withhold the information; however they were "not close" with specific family members, were concerned that they would not be able to explain the genetic information effectively, and/or were concerned that their family members would worry or not understand the relevance of the information to their own health. These barriers have also been reported by other studies of family communication,(26-28) including a recent study looking at communication between parents affected with Lynch syndrome and their offspring.(29)

While these barriers to communication in families may be significant, they can be overcome. (30) Several studies have demonstrated that individuals prefer the involvement of healthcare workers in the process of family communication.(29,31) Genetic counselors are trained to help individuals navigate challenges involved in disseminating information about genetic testing. Pre- and post-test counseling, providing summary letters for patients to distribute to family members, coordinating permissions for release of medical information, and organizing referrals for family members who may live far away can all be helpful for ensuring effective communication about genetic risk.

\section{Challenge \#3: Effective cancer prevention}

The ultimate goal of genetic testing for hereditary CRC is to prevent cancers in a family through endoscopic and surgical interventions. Models have shown that extending the benefits of genetic testing to other relatives makes it even more cost effective. $(32,33)$ However, in order for this information to be of benefit, it must be communicated to the family member, and then the family members must inform their healthcare providers. Studies have shown that many clinicians may not be familiar with the management of different hereditary cancer syndromes. $(34,35)$ Furthermore, until a genetic test result defines the syndrome in the family, individuals at risk for hereditary CRC are often not screened as rigorously as they should be.(36) In addition to frequent CRC surveillance, it is important to realize the need to screen for the various extracolonic cancers associated with many of these hereditary syndromes (Lynch syndrome - endometrial and ovarian cancer, Peutz-Jeghers syndrome - breast, pancreas, and gynecologic cancers, FAP - duodenal, ampullary and thyroid cancers), which may require referrals to other specialists.(8) 
Knowledge that there is a hereditary syndrome in the family could impact the management of individuals diagnosed with polyps or cancers. Because the risk for metachronous CRC in Lynch syndrome is high, patients diagnosed with Lynch-associated CRC may benefit from subtotal colectomy rather than segmental resection.(37) The patient with 20-30 adenomatous polyps removed during yearly colonoscopies may opt to have a total colectomy if the diagnosis of FAP has been made in another family member. Unfortunately, in some families with FAP the death of a parent or sibling is so devastating that at-risk relatives remain in denial about own their risks and the need for increased surveillance. In these families, making a decision about a risk-reducing colectomy may require additional pre-surgical counseling.(38)

It can be helpful to provide patients with a detailed letter outlining specific cancer screening recommendations for patients as well as their relatives who are also at-risk for the hereditary cancer syndrome. Patients should be encouraged to share this letter with their physicians and family members. When patients give providers permission to discuss the family history and genetic test result, this can allow different clinicians caring for a family to communicate directly, while still abiding by privacy requirements.

\section{Challenge \#4: Support of families with hereditary syndromes}

One should not overlook the emotional impact that hereditary cancer risk may have on an individual. Psychosocial distress is not uncommon for individuals with these syndromes and has been well documented in the FAP population.(39) More recent studies have found similar distress among individuals with Peutz-Jeghers syndrome,(40) and one study of individuals at risk for Lynch syndrome demonstrated a tendency toward risky health behaviors, such as smoking, alcohol use, and unhealthy diet.(41) Many patients may not appreciate that the diagnosis of a hereditary cancer syndrome does not represent a "death sentence", and genetic counseling may provide an appropriate venue for a discussion about risk-reducing behavioral modification. $(42,43)$

Many families want to know when their children should undergo genetic testing. Genetic testing is considered in childhood for syndromes that manifest in childhood, including FAP, Peutz-Jeghers syndrome, and Juvenile Polyposis syndrome, because this information would influence medical management. In contrast, for Lynch syndrome there is no reason to consider genetic testing before age 18-20, since CRC surveillance is rarely indicated before age 20. Genetic testing in childhood is ethically challenging for providers and their young patients who may suffer psychological distress related to knowledge about genetic risk. $(44,45)$ Similarly, different adult family members may respond differently to news about a genetic risk, and some may require more psychosocial support throughout the process. Parents may feel guilty about passing a gene mutation to their child, or a person who tests negative for the mutation present in the family may experience survivor guilt. These issues can be managed with appropriate pre- and post-test counseling

Finally, the needs of the patient and his/her family members do change as the family ages, as the next generation starts to have children, and the family tree grows. Several studies have shown that some individuals at risk for hereditary cancer syndromes may be interested in the option of using prenatal testing and/or assisted reproductive technologies such as Preimplantation Genetic Diagnosis (PGD) for future pregnancies. $(46,47)$

\section{Future Directions}

The human genome project has given rise to the promise of personalized medicine. In an effort to screen for hereditary CRC, many institutions have already begun the routine of screening all colorectal tumors for evidence of microsatellite instability and/or deficient 
mismatch repair protein expression associated with Lynch syndrome. In some centers, the result of this "routine" screening is reported as an addendum at the bottom of the surgical pathology report returned to the surgeon.

\section{Consider the following case:}

A patient diagnosed with stage II CRC over a year ago had surgery at one institution, and then went to a different practice for his oncology care. The oncologist never learned of the abnormal MMR protein expression that was reported as an addendum on the revised surgical pathology report. The oncologist claimed that she would have made different recommendations about adjuvant chemotherapy had she known that the patient had Lynch syndrome.

Approximately $15 \%$ of CRC tumors will demonstrate microsatellite instability. Most of these will be due to epigenetic changes and not due to Lynch syndrome, but this cannot be determined without further testing (BRAF V6OOE mutation or $M L H 1$ promoter hypermethylation are common causes of microsatellite instability). Routine tumor screening will raise this question of inherited predisposition for many more CRC patients, and their families, placing the burden on clinicians to interpret and utilize this information appropriately.(48) Many institutions are working to develop strategies for supporting both patients and providers when abnormal results appear. Cancer centers which have established registries for hereditary colorectal cancer syndromes can be helpful in providing expert resources to clinicians, patients, and families.

\section{Conclusion}

The clinical management of families with hereditary CRC can be complex. Even when the diagnosis of genetic predisposition is suspected, confirming the diagnosis may be difficult. When a gene mutation associated with cancer predisposition is identified in a family, genetic counseling may help facilitate family communication and compliance with recommendations for cancer prevention.

\section{Acknowledgments}

Grant Support: NIH-NCI K07 CA 120448-04 Cancer Prevention Control, Behavioral and Population Sciences Career Development Award. (EMS)

\section{References}

1. Jarvinen HJ, Aarnio M, Mustonen H, et al. Controlled 15-Year Trial on Screening for Colorectal Cancer in Families With Hereditary Nonpolyposis Colorectal Cancer. Gastroenterology. 2000; 118(5):829-834. [PubMed: 10784581]

2. Lindor NM, Petersen GM, Hadley DW, et al. Recommendations for the care of individuals with an inherited predisposition to Lynch syndrome: a systematic review. JAMA. 2006; 296(12):15071517. [PubMed: 17003399]

3. NCCN. Clinical Practice Guidelines in Oncology. National Comprehensive Cancer Network; 2010. Colorectal Cancer Screening.

4. Vasen HF, Moslein G, Alonso A, et al. Guidelines for the clinical management of Lynch syndrome (hereditary non-polyposis cancer). J Med Genet. 2007; 44(6):353-362. [PubMed: 17327285]

5. Stoffel EM, Mukherjee B, Raymond VM, et al. Calculation of risk of colorectal and endometrial cancer among patients with Lynch syndrome. Gastroenterology. 2009; 137(5):1621-1627. [PubMed: 19622357]

6. Vasen HF, Nagengast FM, Khan PM. Interval cancers in hereditary non-polyposis colorectal cancer (Lynch syndrome). Lancet. 1995; 345(8958):1183-1184. [PubMed: 7723574] 
7. Jass JR, Stewart SM. Evolution of hereditary nonpolyposis colorectal cancer. Gut. 1992; 33(6):783786. [PubMed: 1624160]

8. Jasperson KW, Tuohy T, Neklason DW, et al. Hereditary and familial colon cancer. Gastroenterology. 2010; 138(6):2044-2058. [PubMed: 20420945]

9. Weissman SM, Bellcross C, Bittner CC, et al. Genetic Counseling Considerations in the Evaluation of Families for Lynch Syndrome-A Review. J Genet Counsel. 2010 Epub.

10. Heinimann K, Scott RJ, Buerstedde JM, et al. Influence of selection criteria on mutation detection in patients with hereditary nonpolyposis colorectal cancer. Cancer. 1999; 85(12):2512-2518. [PubMed: 10375096]

11. Nyström-Lahti M, Wu Y, Moisio AL, et al. DNA mismatch repair gene mutations in 55 kindreds with verified or putative hereditary non-polyposis colorectal cancer. Hum Mol Genet. 1996; 5(6): 763-769. [PubMed: 8776590]

12. Syngal S, Fox EA, Eng C, et al. Sensitivity and specificity of clinical criteria for hereditary nonpolyposis colorectal cancer associated mutations in MSH2 and MLH1. J Med Genet. 2000; 37(9): 641-645. [PubMed: 10978352]

13. de la Chapelle A, Palomaki G, Hampel H. Identifying Lynch syndrome. Int J Cancer. 2009; 125(6): 1492-1493. [PubMed: 19536819]

14. Umar A, Boland CR, Terdiman JP, et al. Revised Bethesda Guidelines for hereditary nonpolyposis colorectal cancer (Lynch syndrome) and microsatellite instability. J Natl Cancer Inst. 2004; 96(4): 261-268. [PubMed: 14970275]

15. Hampel H, Frankel W, Martin E, et al. Feasibility of screening for Lynch syndrome among patients with colorectal cancer. J Clin Oncol. 2008; 26(35):5783-5788. [PubMed: 18809606]

16. Hampel H, Frankel W, Panescu J, et al. Screening for Lynch syndrome (hereditary nonpolyposis colorectal cancer) among endometrial cancer patients. Cancer Res. 2006; 66(15):7810-7817. [PubMed: 16885385]

17. Hampel H, Frankel W, Martin E, et al. Screening for the Lynch syndrome (hereditary nonpolyposis colorectal cancer). N Engl J Med. 2005; 352(18):1851-1860. [PubMed: 15872200]

18. Hampel H, Pancescu J, Lockman J, et al. Comment on: Screening for Lynch Syndrome (Hereditary Nonpolyposis Colorectal Cancer) among Endometrial Cancer Patients. Cancer Res. 2007; 67(19): 9603. [PubMed: 17909073]

19. Hampel H. Point: justification for Lynch syndrome screening among all patients with newly diagnosed colorectal cancer. J Natl Compr Canc Netw. 2010; 8(5):597-601. [PubMed: 20495086]

20. Hall MJ. Counterpoint: implementing population genetic screening for Lynch Syndrome among newly diagnosed colorectal cancer patients--will the ends justify the means? J Natl Compr Canc Netw. 2010; 8(5):606-611. [PubMed: 20495087]

21. Kohonen-Corish M, Weber TK, Lindblom A, et al. Report of the Combined Meeting of the International Society for Gastrointestinal Hereditary Tumours, the Human Variome Project and the National Cancer Institute Colon Cancer Family Registry, Duesseldorf, Germany, 24 June 2009. Fam Cancer. 2010 Epub.

22. Spurdle AB. Clinical relevance of rare germline sequence variants in cancer genes: evolution and application of classification models. Curr Opin Genet Dev. 2010; 20(3):315-323. [PubMed: 20456937]

23. Gaff CL, Clarke AJ, Atkinson P, et al. Process and outcome in communication of genetic information within families: a systematic review. Eur J Hum Genet. 2007; 15(10):999-1011. [PubMed: 17609674]

24. Offit K, Groeger E, Turner S, et al. The "duty to warn" a patient's family members about hereditary disease risks. JAMA. 2004; 292(12):1469-1473. [PubMed: 15383518]

25. Stoffel EM, Ford B, Mercado RC, et al. Sharing genetic test results in Lynch syndrome: communication with close and distant relatives. Clin Gastroenterol Hepatol. 2008; 6(3):333-338. [PubMed: 18258490]

26. Chivers Seymour K, Addington-Hall J, Lucassen AM, et al. What facilitates or impedes family communication following genetic testing for cancer risk? A systematic review and meta-synthesis of primary qualitative research. J Genet Counsel. 2010; 19(4):330-342. 
27. Mesters I, Ausems M, Eichhorn S, et al. Informing one's family about genetic testing for hereditary non-polyposis colorectal cancer (HNPCC): a retrospective exploratory study. Fam Cancer. 2005; 4(2):196-197.

28. Carlsson C, Nilbert M. Living with hereditary non-polyposis colorectal cancer; experiences from and impact of genetic testing. J Genet Counsel. 2007; 16(6):811-820.

29. Aktan-Collan KI, Kaariainen HA, Kolttola EM, et al. Sharing genetic risk with next generation: mutation-positive parents' communication with their offspring in Lynch Syndrome. Fam Cancer. 2010 Epub.

30. Peterson SK, Watts BG, Koehly LM, et al. How families communicate about HNPCC genetic testing: findings from a qualitative study. Am J Med Genet C Semin Med Genet. 2003; 119C(1): 78-86. [PubMed: 12704641]

31. Pentz RD, Peterson SK, Watts B, et al. Hereditary nonpolyposis colorectal cancer family members' perceptions about the duty to inform and health professionals' role in disseminating genetic information. Genet Test. 2005; 9(3):261-268. [PubMed: 16225406]

32. Ramsey SD, Clarke L, Etzioni R, et al. Cost-effectiveness of microsatellite instability screening as a method for detecting hereditary nonpolyposis colorectal cancer. Ann Intern Med. 2001; 135:577-588. [PubMed: 11601929]

33. Mvundura M, Grosse SD, Hampel H, et al. The cost-effectiveness of genetic testing strategies for Lynch syndrome among newly diagnosed patients with colorectal cancer. Genet Med. 2010; 12(2): 93-104. [PubMed: 20084010]

34. Batra S, Valdimarsdottir H, McGovern M, et al. Awareness of genetic testing for colorectal cancer predisposition among specialists in gastroenterology. Am J Gastroenterol. 2002; 97(3):729-733. [PubMed: 11922570]

35. Schroy PC 3rd, Barrison AF, Ling BS, et al. Family history and colorectal cancer screening: a survey of physician knowledge and practice patterns. Am J Gastroenterol. 2002; 97(4):1031-1036. [PubMed: 12008667]

36. Stoffel EM, Mercado RC, Kohlmann W, et al. Prevalence and predictors of appropriate colorectal cancer surveillance in Lynch syndrome. Am J Gastroenterol. 2010; 105(8):1851-1860. [PubMed: 20354509]

37. Kalady MF, McGannon E, Vogel JD, et al. Risk of colorectal adenoma and carcinoma after colectomy for colorectal cancer in patients meeting Amsterdam criteria. Ann Surg. 2010; 252(3): 507-511. [PubMed: 20739851]

38. Neuman HB, Robbins L, Duarte J, et al. Risk-reducing surgery in FAP: role for surgeons beyond the incision. J Surg Oncol. 2010; 101(7):570-6. 1. 101(7):570-576. [PubMed: 20461762]

39. Douma KF, Aaronson NK, Vasen HF, et al. Psychological distress and use of psychosocial support in familial adenomatous polyposis. Psychooncology. 2010; 19(3):289-298. [PubMed: 19382100]

40. van Lier MG, Mathus-Vliegen EM, van Leerdam ME, et al. Quality of life and psychological distress in patients with Peutz-Jeghers syndrome. Clin Genet. 2010; 78(3):219-226. [PubMed: 20695872]

41. Burton AM, Peterson SK, Marani SK, et al. Health and lifestyle behaviors among persons at risk of Lynch syndrome. Cancer Causes Control. 2010; 21(4):513-521. [PubMed: 20012181]

42. Biesecker BB, Marteau TM. The future of genetic counseling: an international perspective. Nat Genet. 1999; 22(2):131-137. [PubMed: 10369252]

43. Lawson P, Flocke S. Teachable moments for health behavior change: a concept analysis. Patient Educ Couns. 2009; 76:25-30. [PubMed: 19110395]

44. Duncan RE, Gillam L, Savulescu J, et al. The challenge of developmentally appropriate care: predictive genetic testing in young people for familial adenomatous polyposis. Fam Cancer. 2010; 9(1):27-35. [PubMed: 19760114]

45. Mireskandari S, Sangster J, Meiser B, et al. Psychosocial impact of familial adenomatous polyposis on young adults: a qualitative study. J Genet Counsel. 2009; 18(5):409-417.

46. Douma KF, Aaronson NK, Vasen HF, et al. Attitudes toward genetic testing in childhood and reproductive decision-making for familial adenomatous polyposis. Eur J Hum Genet. 2009; 18(2): 186-193. [PubMed: 19809485] 
47. Kastrinos F, Stoffel EM, Balmana J, et al. Attitudes toward prenatal genetic testing in patients with familial adenomatous polyposis. AM J Gastroenterol. 2007; 102(6):1284-90. [PubMed: 17355417]

48. Stoffel EM, Chittenden A. Genetic Testing for Hereditary Colorectal Cancer: Challenges in Identifying, Counseling, and Managing High-Risk Patients. Gastroenterology. 2010 Epub. 